\title{
A hermenêutica enquanto diálogo vivo: contribuições para o campo da pesquisa educacional
}

\author{
The hermeneutics as lively dialogue: contributions to the field of educational research
}

\author{
La hermenéutica como diálogo vivo: contribuciones para la investigación \\ en lo campo educativo
}

\author{
Cláudio Almir DALbosco* \\ FERNANDO DALA SANTA** \\ VIVIAN BARONI***
}

\begin{abstract}
RESUMO
Enquanto fenômeno que ocorre no fluxo constante da cultura, a educação incorpora e ao mesmo tempo transforma aspectos essenciais de uma dimensão sociocultural mais ampla, não podendo restringir-se a abordagens que ignorem o caráter contextual da experiência humana. Nessa perspectiva, a hermenêutica traz contribuições importantes para a pesquisa educacional, pois permite a inserção ontológica do pesquisador no contexto analisado, orientando-o a partir de uma conduta pautada na racionalidade própria do fenômeno que se estabelece como objeto da pesquisa. No presente ensaio, procurou-se problematizar os desafios enfrentados pela pesquisa em educação, buscando evidenciar os aportes oferecidos pela hermenêutica como diálogo vivo, centrado na dinâmica da pergunta como núcleo fundante da experiência humana. Intentou-se ainda reiterar a importância do diálogo crítico com a tradição, enquanto estudo dos clássicos, na sua condição de instância imprescindível de um processo intelectual que permita às pesquisas educacionais transcenderem o dogmatismo inerente ao horizonte das pré-compreensões.
\end{abstract}

Palavras-chave: Pesquisa educacional. Hermenêutica. Diálogo.

\begin{abstract}
As a phenomenon that occurs in the steady stream of culture, education incorporates and at the same time transforms essential aspects of a broader socio-cultural dimension, which may not be restricted to approaches that ignore the contextual nature of human experience. In this perspective, hermeneutics brings important contributions to educational research as it allows the insertion of ontological research in the analyzed context, guiding it from a conduct guided by the rationality of the phenomenon that is established as an object of research. In this essay, we try to discuss the challenges faced by educational research to disclosing the contributions offered by hermeneutics as lively dialogue centered on the dynamics of the question as the fundamental core of human experience. We tried to also reiterate the importance of critical dialogue with tradition, while studying the classics in its essential body condition of an intellectual process that allows the educational research transcend the dogmatism inherent in the horizon of preconceptions.
\end{abstract}

Keywords: Educational research. Hermeneutics. Dialogue.

\section{RESUMEN}

Como un fenómeno que se produce en el flujo constante de la cultura, la educación y la incorpora al mismo tiempo transforma aspectos esenciales de una dimensión socio-cultural más amplio, que puede no estar restringido a los enfoques que ignoran la naturaleza contextual de la experiencia humana. En esta perspectiva, la hermenéutica aporta importantes contribuciones a la investigación educativa, ya que permite la inserción de la investigación ontológica en el contexto analizado, guiándolo de una conducta gobernada por la racionalidad del fenómeno que se establece como objeto de la investigación. En este ensayo, tratamos de discutir los desafíos que enfrenta la investigación educativa

\footnotetext{
* Professor do Programa de Pós-Graduação em Educação da Universidade de Passo Fundo - UPF. Pesquisador produtividade do Conselho Nacional de Desenvolvimento Científico e Tecnológico - CNPq.E-mail: cadalbosco@upf.br

**Doutorando em Educação pelo Programa de Pós-Graduação em Educação da Universidade de Passo Fundo - UPF. Bolsista Capes/Prosuc. E-mail: fernandos.101@hotmail.com

***Doutoranda em Educação pelo Programa de Pós-Graduação em Educação da Universidade de Passo Fundo - UPF. Bolsista Capes/Prosuc. E-mail: vivianbaroni@hotmail.com
} 
para revelar las contribuciones ofrecidas por la hermenéutica como animado diálogo centrado en la dinámica de la cuestión como el núcleo fundamental de la experiencia humana. Intentamos también reiteran la importancia de un diálogo crítico con la tradición, mientras que el estudio de los clásicos en su condición corporal esencial de un proceso intelectual que permite la investigación educativa trascender el dogmatismo inherente en el horizonte de ideas preconcebidas.

Palabras clave: Investigación para la educación. La hermenéutica. El diálogo.

\section{CONSIDERAÇÕES INICIAIS}

Na medida em que a educação possui uma realidade institucional, administrativa e organizacional bem definida, mas não uma existência epistemológica específica, as tentativas de definir a natureza do campo investigativo educacional enfrentam ingentes dificuldades. Por se dedicar ao estudo de um fenômeno amplo, cujo foco parte da abordagem de diversas ciências distintas, a pesquisa educacional apresenta-se, nas palavras de Charlot (2006, p. 09), como um campo mal definido, de fronteiras tênues e conceitos difusos; ou, como afirma Gatti (2012, p. 18), "uma geleia geral", referindo-se aos termos pouco precisos utilizados pelos pesquisadores em educação. Tal situação se agrava na contemporaneidade em virtude da adoção de um ideal cientificista de pesquisa, que ao instrumentalizar seu objeto de investigação recai em um relativismo teórico que enfraquece as pretensões de validade do conhecimento educacional.

Ao basear-se cada vez mais nos modelos fornecidos pelas ciências naturais, a pesquisa acaba reduzindo-se a um procedimento metódico-experimental que restringe o estudo do fenômeno educativo ao que é mensurável. Tal modelo, além de não dar conta da amplidão e complexidade do campo educacional, restringe as investigações ao ideal objetivo de cientificidade, levando as pesquisas educacionais a uma inadvertida guinada em direção ao empírico como um dado que fala por si mesmo. Dessa maneira, deixa de perguntar sobre a validade de seus próprios conhecimentos, fragilizando as concepções teóricas que poderiam fundamentar a pesquisa educacional em bases mais sólidas.

Por outro lado, a postura da filosofia como "primeira ciência", ao colocar-se como detentora dos fundamentos últimos da prática pedagógica, estabelece uma hierarquia rígida entre saberes fundantes (filosofia) e fundamentados (pedagogia). Nesse sentido, a pedagogia é vista como um saber cuja base se encontra na filosofia, e não um campo de estudos que guarda autonomia no debate acerca de sua especificidade e que possui ideias próprias com as quais se define como campo de estudo sobre as teorias educativas e sobre a ação educativa. A ênfase da filosofia metafísica conduz a pesquisa no âmbito educacional a um patamar que impossibilita a aproximação com a práxis educativa e a impede de alcançar o horizonte diário da atividade formativa.

Destarte, uma postura unilateral, embasada unicamente em um desses extremos, já não é tolerável nas pesquisas educacionais contemporâneas, pois, conforme Dalbosco (2010, p. 45), a pesquisa empírica sem teoria é cega, ao passo que a pesquisa teórica sem empiria é vazia. Assim, embora sejam princípios distintos de pesquisa, não é possível produzir conhecimento no campo educacional sem levar em conta o equilíbrio entre teoria e prática, que constitui-se por si mesmo numa tensão inesgotável. A hermenêutica, enquanto postura epistemológica baseada no diálogo, propõe uma discussão profícua sobre a problemática da pesquisa, pois não descarta o empírico, considerando-o um saber necessário da experiência, próximo da phrónesis ${ }^{1}$, além de apontar para a importância do resgate da tradição teórica como diálogo entre gerações. Tal perspectiva permite à pesquisa educacional não somente transcender a instrumentalização da prática, mas também ultrapassar o distanciamento da teoria metafísica em relação à práxis. Nesse sentido, a hermenêutica apresenta uma perspectiva que coloca em evidência o diálogo entre epistemologia, técnica e ética, tendo em vista o caráter histórico e falibilista da pesquisa.

\section{BREVE DIAGNÓSTICO DO ATUAL ESTADO DA PESQUISA EDUCACIONAL}

O campo educacional é marcadamente um domínio difuso, de fronteiras indistintas, cuja especificidade mesma parece não apreensível. A esse respeito, Charlot (2006, p. 09) se refere ao caráter mestiço oriundo do entrecruzamento de múltiplos conceitos, métodos, práticas e objetivos distintos que constituem a educação enquanto campo do saber. Para o autor, é justamente em tal mestiçagem que repousa tanto a fraqueza quanto o potencial da educação. Na medida em que se mostra uma disciplina epistemologicamente fraca, de conceitos fluidos e contornos mal definidos, buscando referências

\footnotetext{
1 Entendida aqui como sabedoria prática.
} 
em diversos ramos do conhecimento, a educação torna-se capaz de enfrentar a complexidade e as contradições da sociedade contemporânea. "Quem deseja estudar um fenômeno complexo não pode ter um discurso simples, unidimensional" (CHARLOT, 2006, p. 09).

$\mathrm{O}$ fato de representar um fenômeno plural faz da educação um campo de pesquisas que não admite qualquer espécie de dogmatismo, exigindo um modelo epistemológico-metodológico aberto e flexível. Nesse contexto, mostra-se preocupante a forte inclinação empirista e pragmática observável nas pesquisas realizadas no âmbito da pós-graduação em educação, que centradas no dado concreto e no resultado imediato negligenciam os aspectos teóricos da pesquisa. A perda do vínculo teórico com as reflexões educacionais oriundas da tradição filosófico-pedagógica em nome de um pragmatismo metodológico acarreta, em última análise, "o enfraquecimento das próprias pretensões de validade do conhecimento educacional" (DALBOSCO, 2014, p. 1032).

Conforme Gatti (2012), a fraqueza enfrentada pelo campo educacional nas últimas décadas referese essencialmente ao fato de as pesquisas educacionais terem renunciado à pergunta pela validade do seu próprio conhecimento, abdicando, com isso, do rigor teórico e da qualidade do conhecimento produzido. As pesquisas educacionais encontram dificuldades para aprofundar suas investigações, o que impede que elas visualizem os próprios limites em que estão inseridas. A profusão constante de estudos empíricos que não conseguem ultrapassar a objetividade dos dados, contribuindo para a fraqueza epistemológica que permeia as pesquisas educacionais, parece atestar esse diagnóstico.

Fatores tais como a invasão da economia de mercado no interior da esfera educacional tendem a orientar a pesquisa a partir de parâmetros quantitativos marcados pela mercantilização do ensino, contribuindo para o panorama da fragmentação e fragilização epistemológica que caracterizam o atual estado da pesquisa educacional. A exigência de enxugamento dos currículos e o encurtamento do tempo de formação, aliados ao direcionamento do processo educacional para o mercado de trabalho, contribuem para o crescente pragmatismo e imediatismo que restringe parte da pesquisa educacional à temática da formação de professores.

A preocupação com a objetividade do conhecimento científico, com o claro interesse de eliminar as influências subjetivas do processo investigatório, negligencia, em contrapartida, toda a historicidade presente na noção de experiência humana que compõe a parte mais essencial do processo educativo. A objetificação do seu campo de pesquisa leva a educação a aproximar-se do que Adorno e Horkheimer (1985) chamaram de racionalidade instrumental, ou seja, a autoinstrumentalização do homem, transformado em meio para garantir fins que lhe são alheios. Tal conjuntura traz graves consequências para a pesquisa educacional, na medida em que esta passa a se filiar a uma corrente epistemológica instrumental como fio condutor para a teoria e para a práxis pedagógica. Nas palavras de Flickinger (2010, p.31), a "objetificação e autoinstrumentalização do ser humano apontam para o risco de desviarmos a pedagogia de seu enfoque originário, ou seja, do desenvolvimento da personalidade e sociabilidade do indivíduo".

A natureza instrumental desse enfoque tende a levar cada vez mais as pesquisas educacionais a produzirem conhecimentos pautados na objetividade, que se traduz na profusão de pesquisas de caráter puramente empírico que desprezam os aportes oriundos da tradição teórica clássica. Para Dalbosco, o que está em jogo é o próprio significado de empírico, ou seja, como este é apreendido, interpretado e orientado. Uma análise mais acurada demonstra que o empírico não existe de modo independente, mas é influenciado por inumeráveis componentes internos e externos à pesquisa. O ponto central é que, "ao promover uma 'guinada ao empírico', a pesquisa educacional abandona tendencialmente tais questões (epistemológicas, metodológicas, éticas e políticas), fragilizando com isso suas próprias pretensões" (DALBOSCO, 2014, p. 1037).

No outro extremo das pesquisas educacionais, está a abordagem teórica da filosofia. O conceito metafísico de filosofia (que tem sua origem na filosofia grega e se estende até Hegel) apresenta quatro características distintas, a saber: "Um pensamento em forma de sistema, com pretensões universalistas, baseado numa fundamentação última e que se auto-intitula a primeira ciência" (DALBOSCO, 2007, p. 35). Na sua relação com a educação, a filosofia que parte de uma premissa de ordem metafísica se coloca em uma relação vertical com respeito à pedagogia, derivando uma relação entre fundamentador (filosofia) e fundamentado (pedagogia), na qual o primeiro fornece as bases para explicar e trabalhar os conceitos do segundo. Nesse caso, a pedagogia não é vista em sua especificidade e abandona suas concepções de conhecimento e experiência, tornando-se tão somente um campo de estudos para a filosofia.

A filosofia não pode colocar-se como portadora de uma verdade única capaz de fornecer o aparato teórico base para as outras áreas do conhecimento, pois, dessa maneira, fecha-se em torno de um pretenso universo de verdades essenciais, o que impossibilita o diálogo com as outras ciências. Ademais, o rechaço da prática nega o conhecimento tão importante da experiência que se aproxima do que se denomina acima de sabedoria. A empiria não é somente conhecimento vazio quando se passa a considerar a esfera da práxis como a dimensão para a qual convergem todos os conhecimentos, produções 
e experiências que constroem o universo formativo da educação. Sem considerar a experiência humana da formação, a pesquisa teórica em educação corre o risco de cair na especulação vazia.

O enfrentamento de tal impasse pode se dar na perspectiva da adoção da postura hermenêutica do diálogo: sem querer impor uma determinada posição, mas aceitando o diferente de cada disciplina, o diálogo pressupõe uma postura ética de responsabilidade e respeito mútuos. E o primeiro passo é o reconhecimento da inexistência de um saber único e incondicional, no qual a pesquisa deva se basear irrestritamente. Conforme Flickinger (2010, p. 02), o campo da hermenêutica é "a experiência ontológica do encontro com o outro e a linguagem que se efetua no diálogo". Nesse sentido, a construção do conhecimento é dada no vaivém das considerações, na interlocução e nos raciocínios de cada uma das concepções, respeitando as contribuições advindas das diferentes visões de mundo e de sentidos particulares.

\section{DIÁlOGO E PESQUISA EM EDUCAÇÃo}

É importante destacar, sobretudo, a condição essencialmente social da educação e, como tal, os aportes oferecidos pela tradição hermenêutica no redimensionamento da noção de experiência, "resgatando aquele sentido inerente à condição humana que foi esquecido pela ciência em seu sentido metódicoexperimental" (DALBOSCO, 2014, p. 1032). Com efeito, a hermenêutica se mostra um elemento de importância na efetivação de um modelo de pesquisa educacional capaz de romper com uma perspectiva de análise oriunda das ciências naturais, que tende a arrancar o objeto de seu contexto histórico e adaptá-lo ao método, e para a qual todo conhecimento que não é objetivado e verificável perde seu estatuto de legitimidade. A partir da hermenêutica, a relação entre o sujeito conhecedor e o seu objeto, consequência da objetificação do mundo por parte da razão humana, pode ser colocada em xeque (FLICKINGER, 2010, p. 37).

Desse modo, a hermenêutica ressalta a inseparabilidade entre sujeito e objeto, de maneira que o pesquisador está sempre inserido em um determinado contexto histórico e sociocultural do qual nasce a temática da sua investigação. Ou seja, "a hermenêutica parte do pressuposto que toma como ponto de partida a impossibilidade de o sujeito conhecedor colocar-se fora desse seu contexto querendo distanciar-se dele, a fim de dominá-lo" (FLICKINGER, 2010, p. 157). O princípio que rege essa inseparabilidade no ato da compreensão se refere à inserção do sujeito pesquisador no horizonte da história e da linguagem, uma vez que a expressão do humano é determinada e condicionada pelo horizonte histórico e pela compreensão linguística.
Para Gadamer (1999, p. 559), todo o processo de compreensão é linguístico, no qual a linguagem é o meio sobre o qual se realiza o acordo entre os interlocutores. Nesse sentido, a conversação marca o processo em que os interlocutores buscam chegar a um acordo, e isso envolve a necessidade intrínseca de levar em conta os pontos de vista do outro, de pôr-se no seu lugar, justamente para entender o que ele diz. "O que importa que se acolha é o direito de sua opinião, pautado na coisa, através do qual podemos ambos chegar a nos pôr de acordo com relação à coisa" (GADAMER, 1999, p. 561). A referência central aqui é a própria possibilidade de opinar e supor, ou seja, a abertura, a acolhida à concepção do parceiro de diálogo. Isso remete igualmente à relação exigida ao pesquisador como intérprete dos textos: a reconstrução do texto guiada pela compreensão do que nele se diz.

A ideia de um diálogo vivo presente na hermenêutica gadameriana, pensado como relação franca e simétrica em que os interlocutores constroem conjuntamente novos significados, abre espaço para se pensar nas pesquisas educacionais e no conhecimento humano de modo geral, em seu caráter contingente e falível. $\mathrm{Na}$ concepção de Gadamer, a hermenêutica não é simplesmente um esforço para encontrar um modo adequado de questionar a compreensão histórica e literária dos textos, nos termos em que a compreensão humana é histórica, linguística e dialética (PALMER, 2002, p. 263). Portanto, a hermenêutica gadameriana não se refere a um método de interpretação (como em Schleiermacher), mas à tentativa de inserção ontológica do ser humano no contexto temático a ser analisado (FLICKINGER, 2010, p. 37). Isso denota a impossibilidade de uma pesquisa educacional balizada por uma análise racional que esteja fora da racionalidade a que ela própria se encontra inserida.

O diálogo verdadeiro não pode ser construído se um dos interlocutores possui certezas inquestionáveis; tampouco pode efetivar-se um diálogo entre o pesquisador e o texto de referência se o leitor estiver apenas buscando fundamentação para aquilo que pretensamente já conhece ou se, ao contrário, assume ad literam tudo o que o texto expõe. Do mesmo modo, as pesquisas de campo no âmbito educacional não podem admitir uma relação verticalizada entre o pesquisador e o contexto analisado, nos termos em que é na inter-relação entre as perspectivas de pesquisa e as contingencialidades presentes na realidade escolar que o conhecimento pedagógico se configura. Em um diálogo vivo, é necessário saber ouvir e levar a sério o que está sendo dito, o que exige a aceitação de que a verdade sempre se encontra no caráter processual, na constante reviravolta de argumentos ou na ponderação contínua acerca da legitimação dos raciocínios. De acordo com Flickinger (2014, p. 90), "tal como ocorre na interpretação de um texto que nunca chega a um sentido último e 
'autêntico', os interlocutores do diálogo verdadeiro não passam de intérpretes em busca de um sentido possível e por isso mesmo sempre provisório".

As relações sociais (um jogo de xadrez, um diálogo autêntico, a cooperação interdisciplinar, o vir ao encontro do outro) sempre pressupõem a disposição dos envolvidos em expor-se a experiências imprevisíveis e o impulso de refletir acerca da sua própria postura. Isso implica a obrigatoriedade de um reexame acerca das convicções anteriormente defendidas e a tomada de consciência quanto à sua nova situação e às posturas anteriores. Tal conjuntura demanda a responsabilidade, o reconhecer a autonomia do outro. Nas palavras de Flickinger (2014, p. 104-106), é no conflito entre a chamada "pedagogia da aceitação" e a "pedagogia da resistência" que se percebe o núcleo dessa lógica.

A "pedagogia da aceitação" (FLICKINGER, 2014, p. 104) se refere ao modo tradicional de educação, cuja práxis se faz mediante a aprendizagem de conteúdos já acabados. Nesse conceito de pedagogia, a ênfase é dada no conteúdo como um bloco fechado de verdades dogmáticas. Em tal perspectiva, o pesquisador não leva em conta a falibilidade da teoria, assim como a historicidade inerente à construção do saber. Na hermenêutica, ao contrário, o conhecimento deve ser visto em referência a uma historicidade própria que sempre o determina como um acontecer na tradição. "Com Gadamer estamos situados diante da tarefa de compreender aquilo que se desenvolve como um único grande texto cuja compreensão jamais podemos esgotar" (STEIN, 2011, p. 81).

Opondo-se à perspectiva da "pedagogia da aceitação", aparece a "pedagogia da resistência", que aposta na reformulação da verticalidade entre mestre e aluno, exigindo de ambos o respeito à autonomia e à autenticidade do outro segundo o potencial e nível de atuação de cada um. Sob tal enfoque, a pesquisa é realizada mediante o princípio do diálogo vivo. Nesse esquema, os interlocutores precisam aceitar o risco de expor sua identidade intelectual, não temendo que esta seja colocada em xeque pela intervenção do outro (seja um interlocutor, um texto ou uma situação pedagógica específica), pois assumir o risco de perder o fundamento firme da própria postura intelectual é renunciar também ao direito de ter a última palavra (FLICKINGER, 2014, p. 107).

\section{A PERGUNTA ENQUANTO ELEMENTO FUNDANTE DA POSTURA HERMENÊUTICA: A NECESSIDADE DE TRANSCENDER O HORIZONTE DA PRÉ-COMPREENSÃO}

Toda pesquisa se estrutura mediante um consistente problema de investigação, que, por sua vez, articula-se através de uma pergunta bem formulada. A pergunta pertinentemente estabelecida é aquela que não impõe ou induz a uma resposta, mas que também não se mostra meramente retórica. Caracteriza-se a partir dessa constatação a importância da hermenêutica no tocante à configuração do problema de investigação que baliza as pesquisas educacionais a partir de uma dinâmica dialógica cujo aspecto fundante é a pergunta. "É claro que em toda experiência encontra-se pressuposta a estrutura da pergunta. Não se fazem experiências sem a atividade do perguntar" (GADAMER, 1999, p. 534). Gadamer busca na dialética platônica, com especial referência à maiêutica socrática, o arquétipo de um diálogo que permite o nascimento de sentidos próprios não premeditados. "Chama-se dialética porque é arte de conduzir uma autêntica conversação" (GADAMER, 1999, p. 540).

Isso significa que a pesquisa educacional pensada a partir da hermenêutica, seja ela de âmbito eminentemente teórico ou de características empíricas, conserva um grau de contingencialidade inerente ao seu próprio processo de construção, o qual transcende as convicções iniciais do sujeito pesquisador. Dalbosco (2014, p. 1033) afirma que, na perspectiva da hermenêutica gadameriana, "é pelo diálogo movido pela pergunta de caráter aberto e interminável que o ser humano pode projetar-se além do aspecto dogmático inerente aos modos de experiência ordinária, científica e filosófica". A pergunta aberta quebra com a possibilidade de uma rígida definição $a$ priori da resposta que se pretendia encontrar, evitando que o pesquisador intente conhecer os resultados das pesquisas antes mesmo de iniciá-las. "A abertura do perguntado consiste em que não está fixada uma resposta" (GADAMER, 1999, p. 535).

É inegável que toda pergunta investigativa se encontra intrinsecamente ligada, a um só tempo, ao horizonte da précompreensão e ao âmbito do conhecimento já estabelecido e, por essa razão, não pode ser reflexo senão de um anseio autêntico por conhecer. A aparente contradição presente na afirmação de que a pesquisa educacional se inicia na esfera das nossas opiniões se desfaz ante a tomada de consciência da ambiguidade que lhe é inerente. Dito de outro modo, a pesquisa e, por conseguinte, a construção do conhecimento, desenvolve-se no questionamento constante acerca do corpo de concepções espontâneas e irrefletidas que todos nós carregamos. Historicamente, o fenômeno da pré-compreensão recebeu diversos enfoques e foi definido mediante diferentes conceitos: a doxa aludida no pensamento socrático-platônico, a stultitia em Sêneca, o sensu comunis em Kant, a vivência em Dilthey, a vida cotidiana em Agnes Heller, o senso comum em Gramsci e, finalmente, a pré-compreensão em Gadamer. Tais conceitos possuem em comum o fato de serem compreendidos como o ponto de partida do 
conhecimento (as inquietações que nos levam a pesquisar nascem do solo fértil das experiências cotidianas) e, portanto, reconhecidos como um saber ainda precário e insuficiente, o reino das meias verdades.

Platão, não apenas nos diálogos aporéticos, ditos socráticos, mas inclusive nas obras da maturidade, localiza a doxa, a mera opinião, entre a ciência e a ignorância, pois, mesmo que ainda não seja conhecimento, não é somente obscuridade. A opinião se configuraria, nesse sentido, em uma potência que "permite julgar pelas aparências" (REPÚBLICA, 477e). Assim, quando Sócrates afirma, diante do tribunal que o haveria de condenar à morte, que a mais censurável ignorância seria acreditar saber aquilo que não se sabe (APOLOGIA DE SÓCRATES, 29b), está justamente sustentando a necessidade de não permanecer na esfera da doxa. Sócrates intenta tomar a ignorância em seu sentido positivo, como mola propulsora da busca pelo conhecimento: somente se sente impelido a conhecer quem é capaz de admitir que não conhece plenamente. "Para perguntar, temos que querer saber, isto é, saber que não se sabe" (GADAMER, 1999, p. 535).

Portanto, o caráter ambíguo das opiniões enquanto núcleo da vida cotidiana constitui a instância primária comum, mas não o único horizonte de possibilidades das pesquisas educacionais. Reitera-se que as pesquisas devem obrigatoriamente transcender os limites da consciência espontânea e da experiência imediata, bem como evitar a arrogância de um conhecimento acadêmico pretensamente absoluto, em uma constante e irrestrita autoconstrução. Tal empreendimento se torna possível apenas com a aceitação de que "tanto o 'dado empírico' como a construção conceitual são 'fragmentos' da produção cultural humana que não possuem um sentido a priori, fora das relações humanas, constituídas histórico e socialmente" (DALBOSCO, 2010, p. 45-46).

Gadamer ressalta a importância de se ultrapassar a esfera do saber ordinário da experiência prática, a doxa, em direção a um saber que não é nem científico nem filosófico, mas se aproxima da phrónesis (FLICKINGER, 2014, p. 96). A ênfase de Gadamer no saber da experiência baseia-se em um conhecimento que não é inteiramente objetivável, mas um saber acumulado da biografia do sujeito, que permite o aprendizado sempre novo através das vivências. Esse é o saber da perspicácia do homem experimentado, que the desenvolve a sagacidade e a apreciação certeira, e que no campo da pesquisa permite ao pesquisador potencializar as suas capacidades quando confrontadas com a reflexão teórica (DALBOSCO, 2014, p. 1039-1040). Trata-se ainda de um saber não dogmático que exige do indivíduo não somente o aprendizado, mas também o retorno ao momento inicial, representando um sentido autêntico de experiência.
Portanto, é preciso considerar a interdependência entre teoria e prática, ou seja, a aplicação do saber técnico-científico tem de vir sempre acompanhada do saber flexível da phrónesis, pois é esta que põe em xeque o sentido dogmático do conhecimento técnico-científico (FLICKINGER, 2014, p. 99). Sob essa perspectiva, parece lícito afirmar que a guinada em direção a um modelo de pesquisa que negligencia os aportes teóricos ou que, por outro lado, atém-se unicamente à esfera da teoria acaba por tornar as pesquisas educacionais incapazes de problematizar, em toda a sua ambiguidade, a experiência humana em que se baseiam os processos formativos. E, ao proceder dessa maneira, deixa de confrontar o aspecto dogmático inerente à experiência (DALBOSCO, 2014, p. 1042). O resultado passa a ser a perda do caráter reflexionante da teoria, aprisionando a pesquisa no horizonte inicial da doxa.

Com efeito, ao tomar como referência o diálogo vivo, centrado na dinâmica da pergunta, a hermenêutica permite ao pesquisador a superação das suas crenças não justificadas e a renúncia a quaisquer pretensões de encontrar verdades últimas. Uma pergunta formulada adequadamente é capaz de definir os rumos de um diálogo e determinar a consistência e também a pertinência de uma pesquisa. Flickinger $(2014$, p. 84$)$ ressalta que a pergunta delimita o marco temático, no qual o diálogo se desdobra e influencia sensivelmente no seu sucesso. Nisso repousa a primazia da pergunta em relação à resposta: a arte de perguntar é a arte de pensar (GADAMER, 1999, p. 540). O diálogo se processa na medida em que cada interlocutor aceita o desafio da pergunta lançada pelo outro, e cuja reação, por sua vez, torna-se um novo desafio. Quando se refere à pesquisa bibliográfica, tal panorama dialógico não sofre qualquer alteração, na medida em que "é o próprio texto que nos leva a colocar-lhe perguntas adequadas; que conseguem abri-lo à nossa compreensão. Por isso mesmo, a pergunta adequada é mais importante e difícil do que a resposta certa" (FLICKINGER, 2010, p. 36). Entretanto, o conteúdo do diálogo não se restringe ao que efetivamente vem à tona na conversação. Há uma gama inesgotável de sentidos latentes que subjazem à fala de cada indivíduo, bem como às possíveis significações de um texto. Para Flickinger (2014, p. 76), "a riqueza de sentido nunca se revela somente no dito. A fala sempre carrega consigo sentidos e conotações implícitos, que ficam na clandestinidade, ou seja, por trás do dito".

\section{Pesquisa educacional Amparada EM AUTORES CLÁSSICOS E A CRÍTICA HERMENÊUTICA}

Ora, se a pesquisa educacional desenvolve-se em um constante esforço no sentido de superar nossa pré- 
compreensão, mostra-se pertinente afirmar que a tarefa de resgatar o papel formador da educação é impraticável sem o amparo das reflexões advindas dos autores clássicos. A tradição filosófico-pedagógica transmite um fecundo manancial de conceitos, abordagens e concepções que podem iluminar as discussões educacionais contemporâneas. Não no sentido imediatista de busca por respostas para problemas específicos ou instrumentos de orientação prática, mas como obras que ampliam o nosso horizonte de perspectivas e, por conseguinte, enriquecem nossa visão de mundo. Dalbosco (2010, p. 44) reitera a importância do estudo de autores clássicos na pesquisa educacional ao defender que "o vínculo sistemático da tradição com problemas educacionais atuais permite-lhe a abertura para novos problemas e, por conseguinte, uma reestruturação de seu próprio conteúdo".

Para Calvino (1993, p. 11), "um clássico é um livro que nunca terminou de dizer aquilo que tinha para dizer", que permanece na latência de sentido e provoca, a cada leitura, um novo significado. Os clássicos são obras de deleite estético e de reencontro, com o passado e com nós mesmos, "aquilo que persiste como rumor mesmo onde predomina a atualidade mais incompatível" e permite "entender quem somos e aonde chegamos" (CALVINO, 1993, p. 15-16). Pode-se afirmar que pesquisar o problema educacional no âmbito dos clássicos representa um exercício reflexivo sobre questões cuja validade não se apaga. A pesquisa educacional amparada nos autores clássicos mostra-se profícua na medida em que amplia o alcance do seu espectro teórico ao reforçar o vínculo com a tradição filosófico-pedagógica, fugindo do lugarcomum das atuais pesquisas e da estandardização dos autores de referência.

Com efeito, a hermenêutica demonstra ser imprescindível em um empreendimento intelectual que tenha como horizonte o estudo dos clássicos, no sentido da realização de uma prestação de contas histórico-conceitual de "nossa pré-conceitualidade para o nosso filosofar" (GADAMER, 2009, p. 100), dada a contingencialidade presente na ação de quem investiga, na condição de sujeito restrito ao seu tempo histórico. Tal concepção reforça a importância de buscar compreender além do conteúdo efetivo dos textos, também por que e para quem o autor proferia seus discursos, ou seja, o caráter contextual que talvez indique o sentido mesmo do pensamento do autor. Tal perspectiva se refere ao cuidado acerca do diálogo com a tradição passada, evitando os dogmatismos inerentes à metafísica clássica e à ciência positivista moderna, atentando para a inegável distância temporal, social e cultural que se tem de determinada tradição. Mais do que isso, a importância do diálogo crítico com a tradição não deve ser movido por um interesse puramente exegético ou por uma expectativa imediatista: o fundamento último do diálogo com a tradição é a compreensão da realidade. Nas palavras do próprio Gadamer:

O horizonte do presente não se forma à margem do passado. Nem mesmo existe um horizonte do presente por si mesmo, assim como não existem horizontes históricos a serem ganhos. Antes, compreender é sempre o processo de fusão desses horizontes presumivelmente dados por si mesmo (GADAMER, 1999, p. 457, grifos do autor).

Segundo esse autor, a interpretação de um texto não é uma relação passiva, mas uma interação dialética, uma nova criação, um novo acontecimento na compreensão (PALMER, 2002, p. 262). Na verdade, a relação do leitor (investigador) com o texto é uma entrega ao texto, para buscar o sentido que ele quer lhe mostrar. Mas a essa entrega segue imediatamente o esforço do leitor de querer ir além do sentido do texto, confrontando-o com o próprio sentido que ele cria ao ler o texto. Em princípio, não há um sentido prévio ao texto e nem ao leitor, mas sim aquele é construído pela relação que se estabelece entre ambos. É esse sentido que brota da relação intensa e inesgotável entre leitor e texto que Gadamer chama de fusão de horizontes. Nesse contexto, tal postura de hermenêutica do texto permite analogicamente ao pesquisador ultrapassar o puro formalismo fragmentário das matrizes educacionais empíricas ou puramente teóricas, e pensar um conceito de educação no resgate dos âmbitos ético, intelectual e estético da tradição, em conexão com a realidade em que se estruturam os processos formativos.

Um dos objetivos fundamentais da educação é fomentar nos sujeitos o espírito crítico, demonstrando a necessidade da não aceitação do que é dado como verdade inquestionável. Contudo, deve-se estar atento, evitando a crítica pela crítica, ou seja, distanciando-se de uma nova doutrinação. Para Gadamer, criticar é, sobretudo, pôr à mostra o que se oculta no texto ou na fala criticados, tornando visível o que nela não foi tematizado explicitamente. Pode-se afirmar que a crítica bem fundamentada não recai ela mesma em doutrinação, nem cede sem delongas à opinião oposta, mas obedece a um procedimento reflexivo. Ou seja, seguindo o modelo desenvolvido por Marx, a crítica deve fundamentar-se no diagnóstico feito acerca da teoria levantada, pensada e investigada a partir de si mesma, que então é capaz de demonstrar suas falhas a partir de si mesma. O ponto crucial desse procedimento, antes de opor-se a qualquer teoria, é a crítica que penetra e se alimenta de suas próprias falhas internas. Portanto, o primeiro acesso à teoria criticada é um esforço real de compreender sua construção interna (FLICKINGER, 2014, p. 116). Somente depois dessa compreensão é que o intérprete deve se aventurar a ir além do sentido do texto, criando sua própria interpretação. 
Nesse sentido, a hermenêutica gadameriana indica que a crítica construtiva pressupõe a compreensão do criticado nele mesmo, o que implica a disposição dos envolvidos em expor-se a processos abertos e aprender a suportá-los. Isso não é mais do que o imperativo de renúncia às certezas últimas enquanto fundamento inquestionável da crítica. Flickinger (2014, p. 117-120) destaca três importantes consequências dessa afirmação, intrinsecamente ligadas à questão da pesquisa educacional. Primeiramente, as distintas estruturas institucionais e espaços não formais podem resultar em conflitos entre os diversos campos educativos. A argumentação em favor da postura crítica ressalta a importância das experiências inesperadas que ampliam o leque da aprendizagem e da ação social. Para isso é necessário um movimento de "desorientação", ou seja, questionar as certezas irrevogáveis a fim de identificar os próprios interesses.

A segunda consequência implica a dupla orientação subjacente à postura da crítica construtiva defendida pela concepção hermenêutica: refere-se tanto ao objeto da crítica quanto à base argumentativa daquele que a empreende. Sendo assim, a crítica se revela simultaneamente objetiva e reflexiva. Essas perspectivas dependem ainda uma da outra, isto é, "a crítica apoia-se na experiência da especificidade de seu objeto; e vice-versa, o objeto da crítica só mostra suas peculiaridades mediante a reflexão que, tomando-o a sério, a crítica faz acerca de sua própria base argumentativa" (FLICKINGER, 2014, p. 119). Em tese, a compreensão, a reflexão e a crítica compõem o núcleo articulado da hermenêutica, no qual a falta de um dos elementos inviabiliza os demais.

Já a terceira consequência diz respeito ao abandono de todas as certezas últimas ou verdades inquestionáveis. Assim, cabe considerar o caráter falibilista da teoria. Conforme Paviani (2009, p. 85), a importância da hermenêutica é a de ser crítica da posição absoluta do sujeito, da razão a-histórica. Esta ainda se mostra uma crítica de sua posição crítica, pois descobre em suas condições de possibilidade que é o sujeito que conhece e pensa hermeneuticamente. Desse modo, desloca a prioridade do sujeito para a linguagem, mostrando que a verdade do sujeito encontra-se agora acessível à racionalidade linguística. Em Gadamer, além da questão do método, trata-se de um acesso hermenêutico-filosófico à verdade, isto é, que se abre a esse acesso, na medida em que acredita ser a linguagem o campo da experiência existencial do homem (FLICKINGER, 2014, p. 65).

\section{CONSIDERAÇÕES FINAIS}

No âmbito da pesquisa em educação, dado o caráter multifacetado do fenômeno educativo, mostra-se necessária a adoção de uma postura epistemológica e metodológica que leve em consideração a inegável importância das pesquisas empíricas, bem como dos aportes teóricos da tradição filosófico-pedagógica. Acredita-se que a tão propalada dicotomia entre teoria e prática no contexto educacional é, na verdade, uma falsa dicotomia, que se sustenta unicamente em abordagens que se atêm de modo hermético a apenas um dos elementos constitutivos da pesquisa educacional. Não há como compreender a realidade da prática educacional sem o conhecimento de como tal prática se estrutura no seu desenvolvimento cotidiano, do mesmo modo em que, sem o amparo teórico adequado, as pesquisas empíricas podem não ser capazes de problematizar os dados coletados e, por conseguinte, de transcender a condição de simples descrição da realidade.

Com efeito, a superação das divergências entre as abordagens práticas e teóricas na pesquisa em educação pode ser buscada a partir das contribuições da hermenêutica gadameriana. O diálogo vivo, presente na hermenêutica, permite pensar o conhecimento humano em seu caráter falível e contingente e, desse modo, que a verdade pode ser buscada somente no percurso dialógico percorrido pelos interlocutores. Outro elemento central na concepção hermenêutica é o papel da pergunta como núcleo constitutivo da pesquisa. A pergunta aberta, genuinamente preocupada com a construção de conhecimento, permite vencer a sobreposição de monólogos que caracteriza a relação entre as diversas perspectivas de pesquisa educacional, estabelecendo um diálogo recíproco.

Pode-se afirmar que a interpretação dentro da hermenêutica filosófica compreende sempre a ideia de que não se tem acesso aos objetos simplesmente via significado. Mais do que isso, tem-se acesso aos objetos via significado num mundo histórico determinado, no qual a estrutura lógica nunca dá conta inteiramente da compreensão do conhecimento. Esse fato ressalta a completude do método hermenêutico em não ficar preso ao estritamente racional, mas considerar a empiria como um elemento importante a ser levado em conta no momento da interpretação.

Demostra aqui sua importância o conceito de experiência que se depreende da postura hermenêutica, que não é um conhecimento puramente técnico, mas que se refere à sabedoria prática (phrónesis), algo próximo a uma interpretação de mundo que transcende a instrumentalização da prática e a abstração da teoria. Nesse sentido, a pesquisa educacional não pode desprezar a empiria, aquilo que efetivamente representa a realidade escolar em sua dinâmica efervescência, mas também não pode se restringir a esta, devendo imperiosamente buscar, sempre que necessário, subsídios na tradição. Portanto, nos termos da pesquisa educacional, a exigência feita 
pela hermenêutica é a superação do horizonte da précompreensão, através do diálogo crítico com a tradição teórica, com o clássico. Dessa maneira, a hermenêutica ressalta também a figura ideal do pesquisador como homem experimentado, que consegue conjugar a um só tempo teoria e prática, porque justamente por ser um ser humano experimentado aprendeu pela sua perspicácia a dimensão inesgotável e tensional da relação entre teoria e prática.

\section{REFERÊNCIAS}

ADORNO, Theodor; HORKHEIMER, Max. Dialética do esclarecimento: fragmentos filosóficos. Rio de Janeiro: Jorge Zahar Editor, 1985.

CALVINO, Ítalo. Por que ler os clássicos. Trad. Nilson Moulin. São Paulo: Companhia das Letras, 1993.

CHARLOT, Bernard. A pesquisa educacional entre conhecimentos, políticas e práticas: especificidades e desafios de uma área de saber. Revista Brasileira de Educação, v. 11, n. 31, p. 7-18, jan./abr. 2006.

DALBOSCO, Cláudio A. Pedagogia filosófica: cercanias de um diálogo. São Paulo: Paulinas, 2007.

DALBOSCO, Cláudio A. Natureza da pesquisa em educação: abrindo um leque de alguns problemas. In: HENNING, Leoni M. P. (Org.). Pesquisa, ensino e extensão no campo filosóficoeducacional: possibilidades presentes no contexto universitário. Londrina: Eduel, 2010. p. 41-66.

DALBOSCO, Cláudio A. Pesquisa educacional e experiência humana na perspectiva hermenêutica. In: Cadernos de Pesquisa (Fundação Carlos Chagas), v. 44, n. 154, p. 1028-1051, 2014.
FLICKINGER, Hans-Georg. A caminho de uma pedagogia hermenêutica. Campinas: Autores Associados, 2010.

FLICKINGER, Hans-Georg. Gadamer e a educação. Belo Horizonte: Autêntica, 2014.

GADAMER, Hans-Georg. Verdade e método: traços fundamentais de uma hermenêutica filosófica. Trad. Flávio Paulo Meurer. 3. ed. Petrópolis: Vozes, 1999.

GADAMER, Hans-Georg. Hermenêutica em retrospectiva. Trad. Marco Antônio Casanova. Petrópolis: Vozes, 2009.

GATTI, Bernardete A. A construção metodológica da pesquisa em educação: desafios. RBPAE, v. 28, n. 1, p. 13-34, jan./abr. 2012.

PALMER, Richard E. Que es la herméneutica? Teoria de la interpretación en Schleiermacher, Dilthey, Heidegger e Gadamer. Trad. Beatriz Domíngues Parra. Madrid: Arco/Libros, 2002.

PAVIANI, Jayme. Epistemologia prática: ensino e conhecimento científico. Caxias do Sul: Educs, 2009.

PLATÃO. A República. Trad. Maria Helena da Rocha Pereira. 9. ed. Lisboa: Fundação Calouste Gulbenkian, 2001.

PLATÓN. Diálogos I: Apología, Critón, Eutifrón, Ion, Lisis, Cármides, Hipias menor, Hipiasmayor, Laques, Protágoras. Madrid: Editorial Gredos, 1985.

SCHLEIERMACHER, Friedrich Daniel Ernst. Hermenêutica: arte e técnica da interpretação. Trad. Celso Reni Braida. Petrópolis: Vozes, 2000.

STEIN, Ernildo. Inovação na filosofia. Ijuí: Ed. Unijuí, 2011.

Recebido em 19-08-2016

Aprovado em 09-03-2018. 